\title{
BMJ Open Return on investment of a model of access combining triage with initial management: an economic analysis
}

David A Snowdon (D) , ${ }^{1,2}$ Katherine E Harding, ${ }^{2,3}$ Nicholas F Taylor (D) ${ }^{2,3}$
Sandra G Leggat (D) ,", ${ }^{4,5}$ Bridie Kent, ${ }^{6}$ Annie K Lewis, ${ }^{2,3}$ Jennifer J Watts (D) ${ }^{7}$

To cite: Snowdon DA, Harding KE, Taylor NF, et al. Return on investment of a model of access combining triage with initial management: an economic analysis. BMJ Open 2021;11:e045096. doi:10.1136 bmjopen-2020-045096

- Prepublication history and additional supplemental material for this paper are available online. To view these files, please visit the journal online (http://dx.doi.org/10.1136/ bmjopen-2020-045096).

Received 22 September 2020 Accepted 05 July 2021

Check for updates

(c) Author(s) (or their employer(s)) 2021. Re-use permitted under CC BY-NC. No commercial re-use. See rights and permissions. Published by BMJ.

For numbered affiliations see end of article.

Correspondence to Dr David A Snowdon; david.snowdon@monash.edu

\section{ABSTRACT}

Objectives Timely access to outpatient services is a major issue for public health systems. To address this issue, we aimed to establish the return on investment to the health system of the implementation of an alternative model for access and triage (Specific Timely Appointments for Triage: STAT) compared with a traditional waitlist model.

Design Using a prospective pre-post design, an economic analysis was completed comparing the health system costs for participants who were referred for community outpatient services post-implementation of STAT with a traditional waitlist comparison group.

Setting Eight community outpatient services of a health network in Melbourne, Australia.

Participants Adults and children referred to community outpatient services.

Interventions STAT combined targeted activities to reduce the existing waiting list and direct booking of patients into protected assessment appointments. STAT was compared with usual care, in which new patients were placed on a waiting list and offered appointments as space became available.

Outcomes Health system costs included STAT implementation costs, outpatient health service use, emergency department presentations and hospital admissions 3 months before and after initial outpatient appointment. Waiting time was the primary outcome. Incremental cost-effectiveness ratios (ICERs) were estimated from the health system perspective.

Results Data from 557 participants showed a 16.9 days or $29 \%(p<0.001)$ reduction in waiting time for first appointment with STAT compared with traditional waitlist. The ICER showed a cost of $\$ A 10(95 \% \mathrm{Cl}-19$ to 39) per day reduction in waiting time with STAT compared with traditional waitlist. Modelling showed the cost reduced to $\$ A 4$ (95\% Cl -25 to 32) per day of reduction in waiting, if reduction in waiting times is sustained for 12 months. Conclusions There was a significant reduction in waiting time with the introduction of STAT at minimal cost to the health system.

Trial registration number Australian New Zealand Clinical Trials Registry (ACTRN12615001016527).

\section{INTRODUCTION}

Prolonged waiting times present a challenge for community-based public health services

\section{Strengths and limitations of this study}

- Economic evaluation of an alternative model for access and triage (Specific Timely Appointments for Triage) that has reduced waiting times for community outpatient services.

- Economic evaluation nested within a larger steppedwedge randomised controlled trial with participants blind to intervention.

- Study conducted across a diversity of publicly funded community outpatient services increasing the generalisability of the findings.

- Limited to economic evaluation from a health service perspective.

and the patients who seek these services. ${ }^{1-4}$ Delays in care are the result of a discrepancy between demand for a service and the capacity of the service to meet this demand. ${ }^{5}$ Lack of capacity may reflect insufficient resources to provide the necessary services, but can also be due to suboptimal use of available resources. ${ }^{6} 7$ When this discrepancy is not addressed, queues or waiting lists are formed. ${ }^{8}$ Where waiting lists continue to grow, this is likely to indicate an ongoing imbalance between supply and demand. However, if there is a short-term disruption to supply, a waiting list might develop that becomes stable over time, suggesting that supply and demand may be balanced but with the response to new referrals always weeks or months behind. These queues delay access to community-based services with detrimental effects on patient outcomes including physical, psychological health and well-being, with associated economic costs. ${ }^{9-13}$

Two common approaches to managing waiting lists are short-term increases in supply to reduce the waiting list and implementation of triage and prioritisation systems to sort patients according to their urgency of care. ${ }^{714}$ Temporary increases in supply without ongoing changes to service 
delivery only resolve the issue in the short term; inefficient processes, lack of protected appointments for new patients and temporary disruptions to supply mean that waiting lists soon reappear. ${ }^{7}$ Triage systems may ensure that urgent patients have access to care, but make limited difference to waiting times overall and those classified as 'low priority' in triage systems may never receive care. ${ }^{14}$ Neither of these strategies address the discrepancy between supply and demand over the long term. ${ }^{15}$

Models that actively address both the existing waiting list and the suboptimal use of resources for ongoing care have had success in reducing waiting times. ${ }^{16}{ }^{17}$ The Specific Timely Appointments for Triage (STAT) model is one example, which reduced waiting time by $34 \%$ across eight community outpatient services in a stepped-wedge cluster randomised controlled trial. ${ }^{17}$ The fundamental principle of STAT is that the rate of demand is calculated, and the number of new appointments required each week to keep up with demand is protected in clinician schedules. This is complemented by a short-term, targeted intervention to reduce or clear the backlog of waiting patients prior to the introduction of protected appointments for new patients. These processes reduce waiting times by ensuring that there is a balance between supply and demand. The STAT model is different from open or advanced access models that leave appointments open for new patients in that all appointments are scheduled, ${ }^{18}$ with new patients receiving a scheduled appointment when their referral is received. The STAT model addresses identified weaknesses of the open access models, especially concerns related to lack of continuity of care. ${ }^{18}$

While STAT has been demonstrated to be effective in reducing waiting time across a variety of community outpatient services, ${ }^{17}$ policymakers need information about the cost implications of the model in order to make informed decisions about the return on investment of implementation from a health system perspective. STAT does not require any ongoing resources, but there are short-term implementation costs involved in reducing the existing backlog. It is unknown if the investment in resources to reduce the backlog of waiting patients is offset by savings in the community outpatient episode of care. A further complexity in evaluating the costs of the STAT model is that the costs of implementation occur as an upfront investment but the benefits are realised by patients who attend the service in the future, through reduced waiting time impacting on health and well-being. Return on investment is, therefore, determined not just from the immediate impact on the health service but by the number of patients who subsequently benefit. This in turn is dependent on the amount of time after the initial investment that reductions in waiting time can be sustained.

We aimed to complete cost-effectiveness analyses, using data from two cohorts of patients who attended the participating services before and after the introduction of the STAT model. The primary aim was to determine, from a health system perspective, the return on investment of implementing the STAT model, compared with a traditional model of access and triage. Sustainability of benefits was modelled over 3, 6 and 12 months post-implementation.

\section{METHODS \\ Design}

A prospective pre-post economic study was nested within a larger stepped-wedge cluster randomised controlled trial. ${ }^{1617}$ Routinely collected data informed the analysis of the larger trial while the economic component involved intensive patient-level data collection. As such, it was not possible to collect economic data from all patients who participated in the larger stepped-wedge trial, instead economic data were collected from a sample of patients at each site. These data were collected from outpatients who received an initial appointment when a traditional waitlist and triage model operated, and an independent cohort who commenced care within 9 months post-STAT implementation.

The trial, including this nested pre-post economic study, was registered prospectively with the Australian and New Zealand Clinical Trials Registry and the report has been prepared with reference to the Consolidated Health Economic Evaluation Reporting Standards checklist. ${ }^{19}$

\section{Patient involvement}

Patients were involved in the conduct of this research. During the trial, a patient joined the independent trial steering committee. Once the trial has been published, participants will be informed of the results through a research group's website (www.stat.trekeducation.org).

\section{Setting}

Eight community outpatient services of a public health network providing care to a population of more than 700000 people in eastern Melbourne, Australia, that extended into adjacent rural communities, participated. The community outpatient sites all offered allied health, medical and/or nursing therapy services (most within multidisciplinary teams); provided care over a series of appointments; prior to the implementation of STAT had used waiting lists with triage systems to manage demand; and had stable waiting lists over the previous 2 years. Services meeting these criteria were selected from 28 community outpatient services within the network that participated in a preliminary study exploring perceptions of factors that affect waiting lists. ${ }^{4}$ The eight services provided the following specialty clinical services: continence $(n=2)$, movement disorders $(n=1)$, developmental disorders $(\mathrm{n}=1)$ and mixed (orthopaedics/neurological/ general frailty $(n=4)$. They included a mixture of single discipline $(n=3)$ and multidisciplinary $(n=5)$ services, and provided healthcare to paediatric $(n=3)$, adult $(n=4)$ and mixed $(n=1)$ populations. ${ }^{17}$ 


\section{Patients and recruitment}

Between October 2015 and June 2017, outpatients attending their first outpatient visit were recruited from the eight services. Potential participants were approached consecutively to provide economic and quality of life data during their first clinic visit. Recruitment continued at each service until the target sample size was reached, or until the conclusion of the trial period. If unable to give written informed consent due to cognitive or communication impairments, or age $(<18$ years of age), their guardian or responsible person was approached to provide written consent on their behalf. Outpatients were blinded to whether they were attending the service within the traditional waitlist or STAT period.

\section{Intervention}

During the pre-STAT implementation period, all services used a traditional waitlist and triage system (termed a traditional waitlist model) to manage access, where outpatients who were deemed to have a 'low' need had a longer wait to access the service than outpatients who were deemed to have a 'high' need. Appointments were offered to new patients as they could be accommodated in clinician schedules. There were no systems in place to match supply (ie, number of appointments required for new patients) with demand (ie, number of new patients referred).

The intervention (STAT) has been described in detail previously. ${ }^{16}$ STAT involved the following steps:

- Short-term strategies to reduce the existing waiting list: participating services were provided with small injection of resources to assist with reducing backlog. Services were permitted to use these resources in whatever way they deemed most effective (eg, employing additional short-term staff, contracting work to private providers). These resources were provided in the short term only (ie, 3 months) and no additional ongoing resources were provided. Existing patients who remained on the waiting list following this shortterm reduction strategy were assigned the next available appointment, consistent with the STAT model.

- Demand calculated: the rate of demand and number of new appointments required each week to keep up with this demand was calculated based on historical data, including an allowance of additional appointments, to account for time lost due to staff leave and statutory holidays.

- Required appointments protected: the appointments required to keep up with demand were protected in clinician schedules. New patients were allocated to these appointments immediately after referral in order of arrival. Triage processes were scaled back or ceased and booking processes were simplified, although most services maintained systems for 'emergency' appointments to accommodate very urgent patients if required.

- Prioritisation of resources in the context of demand: prioritisation decisions shifted from priority of access to the service to a focus on priority of need for ongoing services after the initial appointment. The treating clinician made a decision using clinical judgement of the patient's need for ongoing services and within the context of the known demand for service.

\section{Health system costs}

Costs to the health system (in 2017 Australian dollars) in STAT and the traditional waitlist model over 6 months were determined from services used by the patient in the 3 months prior to their first appointment and the 3 months after their first appointment.

The 3-month period prior to the first appointment for each participant was important because people who waited longer for their first appointment may have had a higher use of alternative services, such as visits to the emergency department. Three months after first appointment was important because people who waited longer may have subsequently required more intensive services to treat their condition.

A standardised questionnaire developed for the study was administered to participants during their first appointment. The health service utilisation questionnaire asked participants about the number of appointments received from other health services, the number of emergency department presentations and the number of nights admitted to hospital in the previous 3 months. Information from health service utilisation questionnaires was compared with participant medical records from the previous 3 months to check data accuracy.

Health service utilisation data in the 3 months after the first appointment were obtained using routinely collected data rather than a participant questionnaire due to practical difficulties obtaining adequate response rates from follow-up questionnaires. Medical records were audited to determine the number of appointments received from the participating health network, as well as the number of emergency department presentations and the number of nights admitted to hospital.

Health service use external to the participating health network during the 3 months prior to the first appointment was costed at consultation rates for private health practitioners, ${ }^{2021}$ and the cost to the participating health network was costed at consultation rates for public service health practitioners. ${ }^{22}$ Cost of emergency department presentations was based on the price for non-admitted triage category $4 .{ }^{23}$ The cost of a hospital admission was calculated at a per diem rate, by dividing the average total cost of admission by the average length of stay (table 1). ${ }^{24}$ Health service utilisation costs for the 3 months before and after the first appointment were summed for each outpatient to calculate the cost to the health system.

The only cost of implementing STAT was the cost involved in providing the initial targeted intervention to reduce the waiting list. The cost of implementation was calculated per patient at each of the eight services by dividing the cost of the STAT backlog reduction activities at each service by the total number of patients 
Table 1 Costs Included in the economic evaluation in 2017 \$A

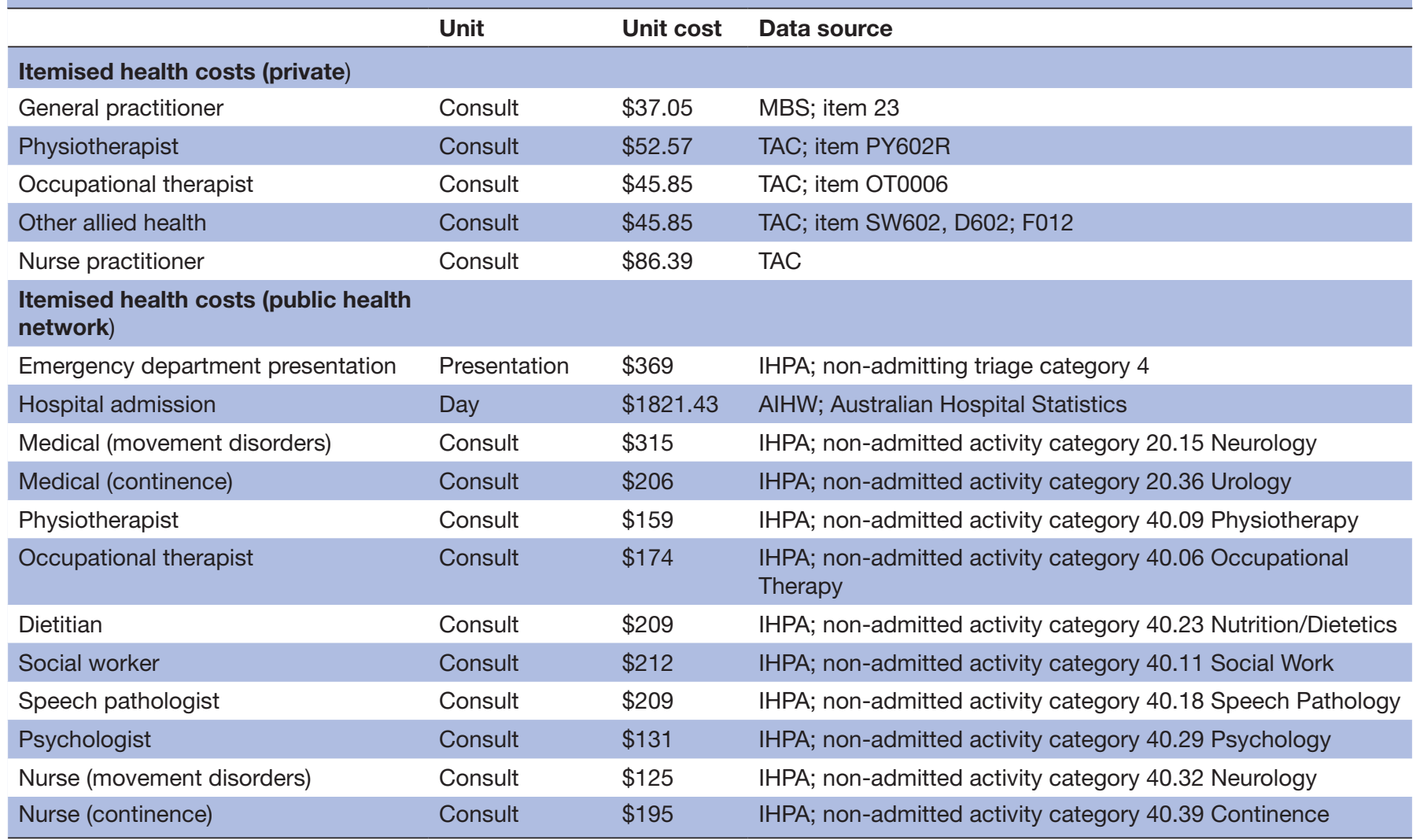

AlHW, Australian Institute of Health and Welfare; IHPA, Independent Hospital Pricing Authority; MBS, Medicare Benefits Scheme; TAC, Transport Accident Commission.

commencing services during the first 3 months of STAT. The total number of new patients at each service was obtained from the larger trial. ${ }^{16}$

The total cost of implementing the STAT intervention was \$A72 049 across the eight services. This equated to a weighted average cost of approximately $\$ A 105$ per patient over a 3-month period, ranging from $\$ A 6$ to $\$ A 358$ per patient at individual sites. The weighted average cost reduced to $\$ \mathrm{~A} 52.50$ or $\$ \mathrm{~A} 26.25$ per patient if distributed over 6 months or 12 months, respectively. To calculate the cost of care per patient during the post-implementation period, the 'per patient' implementation cost for each service was added to the direct cost of the health service that each participant received.

The return on investment of STAT was modelled at 6 and 12 months post-implementation with the assumption that demand was constant (number of outpatients referred) and the reduction in waiting time was sustained. Within these models, the per patient cost of implementing STAT was calculated for each time period by doubling the number of outpatients for the 6-month model, and multiplying by 4 for the 12-month model.

\section{Outcome measures}

The key outcome contributing to the economic analyses was waiting time, measured as the number of days from referral to first appointment.
The Assessment of Quality of Life (AQOL-8D) instrument was used to obtain a physical, mental and global utility score for quality of life, ${ }^{25} 26$ to provide a broad indication of the health status of participants. The AQOL-8D was administered on the day of the first outpatient appointment. During the administration of the AQOL$8 \mathrm{D}$, the participant was asked to reflect on the previous week.

Participant demographics including age, sex, informal care needs, receipt of government benefits, referral reason, referral source, health professional discipline conducting first appointment and discharge status at 3 months after the initial assessment were collected from medical records.

\section{Sample size}

We aimed to sample 40 participants at each site during the traditional waitlist and STAT periods. Since costeffectiveness was based on return on investment for each day of waiting time reduced post-STAT implementation compared with traditional waitlist model, sample size was based on waiting time. It was estimated that a sample of 640 participants (320 in each group) would provide greater than $99 \%$ power to detect a reduction in waiting time of one-third from a traditional waitlist model of 18 days (SD 12) at an alpha level of $0.05 .^{27}$ 


\section{Statistical analysis}

Between-group differences in waiting time and health system costs were calculated with analysis of covariance (ANCOVA) using service as a covariate to account for clustering. Incremental cost-effectiveness ratios (ICERs) represent the difference in cost between the STAT and traditional waitlist periods, divided by the difference in their effect (waiting days saved). ICERs were calculated from waiting time using mean differences derived from ANCOVA.

CIs around ICERs were calculated using the bootstrap method (5000 repetitions), the difference in waiting time between STAT and traditional waitlist, and cost from health system perspectives. ${ }^{28}$ Individual ICERs were used to generate confidence ellipses using the central limit theorem. ${ }^{28}$ The ellipses provide information relating to the statistical significance of the intervention (STAT) being investigated.

Patient demographics were compared using $\mathrm{X}^{2}$ for categorical/binary data and t-tests for continuous data.

Analyses were completed using IBM SPSS statistics V.24, ${ }^{29}$ and customised software in Microsoft Excel. ${ }^{28}$ Statistical tests were conducted at 0.05 level of significance and described using 95\% CIs.

\section{RESULTS}

Economic data were collected from 557 participants; 278 traditional waitlist participants and 279 STAT participants.

\section{Baseline characteristics}

The groups were similar for sex, age, referral reason, referral source, number of missed appointments, proportion discharged from the health network within 3 months of first appointment and proportion receiving informal care (table 2). More traditional waitlist participants had their first appointment with a nurse, while more STAT participants had their first appointment with a medical practitioner. The proportion of participants receiving government benefits was significantly lower with STAT compared with traditional waitlist.

The mean (SD) AQOL-8D global utility score was 0.71 $(0.21)$ in the STAT group and $0.68(0.20)$ in the traditional waitlist group (mean difference $0.03, \mathrm{p}=0.066$ ).

The characteristics of the participating outpatient services can be viewed in online supplemental file 1 .

\section{Health system costs}

The mean total cost was $\$ A 165$ (95\% CI -261 to 592, $\mathrm{p}=0.447$ ) greater with STAT compared with traditional waitlist. This cost was attributable to the cost of implementing STAT, as there were no differences in the cost of hospital admissions, emergency department attendance or outpatient health professional service use. The mean cost per patient of implementing STAT distributed over 3 months of new patient admissions was \$A121 (SD \$91) (table 3).

\section{Waiting time}

There was a significant reduction in waiting time for STAT participants (mean: 40.8 days, SD: 31.3), who waited, on
Table 2 Participant characteristics at baseline in traditional waitlist and STAT groups

\begin{tabular}{|c|c|c|c|}
\hline & $\begin{array}{l}\text { Traditional } \\
\text { waitlist } n=278\end{array}$ & STAT $n=279$ & \multirow[b]{2}{*}{$P$ value } \\
\hline & n (\%) & n (\%) & \\
\hline Sex (female) & $155(56)$ & $161(58)$ & 0.642 \\
\hline Age $^{*}$ (years) & $37(32)$ & $38(32)$ & 0.864 \\
\hline Referral reason & & & 0.743 \\
\hline Musculoskeletal & $63(23)$ & $73(26)$ & \\
\hline Neurological & $24(9)$ & $25(9)$ & \\
\hline $\begin{array}{l}\text { Developmental } \\
\text { assessment }\end{array}$ & $101(36)$ & $90(32)$ & \\
\hline Incontinence & $79(28)$ & $83(30)$ & \\
\hline $\begin{array}{l}\text { General function } \\
\text { (falls, mobility, home } \\
\text { assessment) }\end{array}$ & $11(4)$ & $8(3)$ & \\
\hline Referral source $\dagger$ & & & 0.325 \\
\hline Hospital & $36(13)$ & $29(10)$ & \\
\hline Medical practitioner & $80(29)$ & $66(24)$ & \\
\hline Self/relative/carer & $34(12)$ & $36(13)$ & \\
\hline $\begin{array}{l}\text { Community service } \\
\text { provider }\end{array}$ & $128(46)$ & $147(53)$ & \\
\hline
\end{tabular}

\begin{tabular}{|c|c|c|c|}
\hline $\begin{array}{l}\text { First discipline } \\
\text { appointment }\end{array}$ & & & 0.017 \\
\hline Physiotherapist & $166(60)$ & $172(62)$ & \\
\hline $\begin{array}{l}\text { Occupational } \\
\text { therapist }\end{array}$ & $14(5)$ & $12(4)$ & \\
\hline Speech pathologist & $38(14)$ & $43(15)$ & \\
\hline Nurse & $49(18)$ & $26(9)$ & \\
\hline Medical & $6(2)$ & $20(7)$ & \\
\hline Social worker & $4(1)$ & $4(1)$ & \\
\hline Dietitian & $1(<1)$ & $2(1)$ & \\
\hline $\begin{array}{l}\text { Discharged from health } \\
\text { service within } 3 \text { months } \\
\text { of } 1 \text { st appointment }\end{array}$ & $112(40)$ & $97(34)$ & 0.178 \\
\hline Missed appointments ${ }^{\star}$ & $0.27(0.96)$ & $0.25(0.71)$ & 0.76 \\
\hline $\begin{array}{l}\text { Received government } \\
\text { benefits }\end{array}$ & $181(65)$ & $154(55)$ & 0.017 \\
\hline Received informal care & $56(20)$ & $62(22)$ & 0.548 \\
\hline \multicolumn{4}{|l|}{$\begin{array}{l}\text { AQOL-8D* (units) (n } \\
\text { pre/n post) }\end{array}$} \\
\hline $\begin{array}{l}\text { Physical dimension } \\
\text { utility }(276 / 277)\end{array}$ & $0.63(0.24)$ & $0.65(0.24)$ & 0.288 \\
\hline $\begin{array}{l}\text { Mental dimension utility } \\
(276 / 272)\end{array}$ & $0.39(0.19)$ & $0.42(0.19)$ & 0.078 \\
\hline $\begin{array}{l}\text { Global utility } \\
(276 / 271)\end{array}$ & $0.68(0.20)$ & $0.71(0.21)$ & 0.066 \\
\hline
\end{tabular}

${ }^{*}$ Reported as mean (SD).

†One missing data point, data calculated from 278 participants.

AQOL-8D, Assessment of Quality of Life; STAT, Specific Timely Appointments for Triage.

average, 16.9 days less for their first appointment than traditional waitlist participants (mean: 57.7 days, SD: 49.3, $\mathrm{p}<0.001)$. Weighted mean waiting time for the participants in the 10th percentile (ie, those that waited the least amount of time) was 1.1 days longer in the STAT 
Table 3 Mean total cost (SD) of groups and mean $(95 \% \mathrm{Cl})$ difference between groups $(\$ A)$ from a health system perspective at 3 months

\begin{tabular}{|c|c|c|c|c|}
\hline Perspective & \multicolumn{2}{|c|}{ Groups } & $\begin{array}{l}\text { Difference between groups } \\
\text { Mean difference } \\
(95 \% \mathrm{Cl})\end{array}$ & $P$ value \\
\hline Total cost & $1324(2755)$ & $1486(2383)$ & $165(-261$ to 592$)$ & 0.447 \\
\hline 12 weeks before 1 st appointment & $648(2584)$ & $635(1962)$ & $-13(-395$ to 370$)$ & 0.949 \\
\hline Hospital admission & $197(2354)$ & $144(1592)$ & $-52(-387$ to 282$)$ & 0.758 \\
\hline Emergency department attendance & $125(226)$ & $110(224)$ & $-15(-52$ to 22$)$ & 0.418 \\
\hline 12 weeks after 1 st appointment & $676(965)$ & $851(1036)$ & $178(16$ to 316$)$ & 0.031 \\
\hline Hospital admission & $128(834)$ & $167(823)$ & 39 (-99 to 177$)$ & 0.579 \\
\hline Emergency department attendance & $56(180)$ & $77(173)$ & 21 (-8 to 51$)$ & 0.155 \\
\hline Outpatient health professional service & $492(439)$ & $486(392)$ & $-4(-66$ to 51$)$ & 0.900 \\
\hline
\end{tabular}

Between-group mean difference calculated using service as a covariate. STAT, Specific Timely Appointments for Triage.

group (10.0 days) compared with the traditional waitlist group ( 8.9 days). Weighted mean waiting time for participants in the 90th percentile (ie, those that waited the most amount of time) was 46.1 days shorter in the STAT group (86.0 days compared with the traditional waitlist group (132.1 days).

\section{Incremental cost-effectiveness ratios}

From a health system perspective, the ICER showed a cost of $\$ A 10(95 \%$ CI -19 to 39$)$ per day of reduction in waiting time with STAT compared with traditional waitlist. The ICER ellipses for confidence bands of 50\%, $75 \%$ and $95 \%$ show that all CIs are distributed between the lower and upper right quadrants (figure 1$).^{30}$

\section{Cost-effectiveness acceptability curve}

The cost-effectiveness acceptability curve shows that there was a $50 \%$ probability that the additional cost of STAT, compared with traditional waitlist, was at or below $\$ \mathrm{~A} 10$ per day of waiting saved (figure 2).

\section{Modelling of effect at 6 months and 12 months post- implementation}

If the costs of implementation of STAT are distributed over 6 months, the ICER shows a cost of \$A6 (95\% CI -22 to 34$)$ per day of reduction in waiting time (table 4). The curve shows a $61 \%$ probability that the additional cost of STAT, compared with a traditional waitlist, was at or below $\$$ A10 per day of waiting saved.

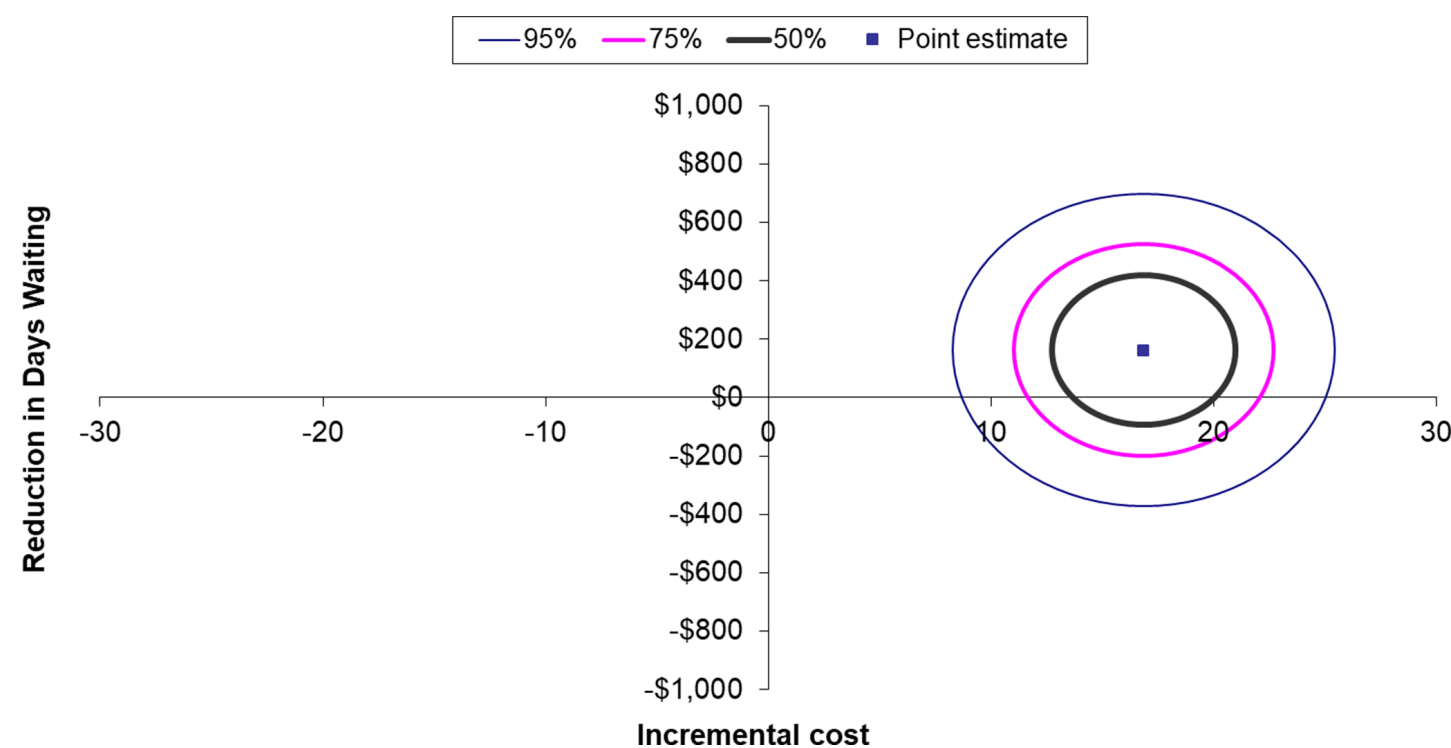

Figure 1 Confidence ellipses STAT versus traditional waitlist for the incremental health system cost ( $\$ A$ ) (vertical axis) per day reduction in waiting time (horizontal axis). STAT, Specific Timely Appointments for Triage. 


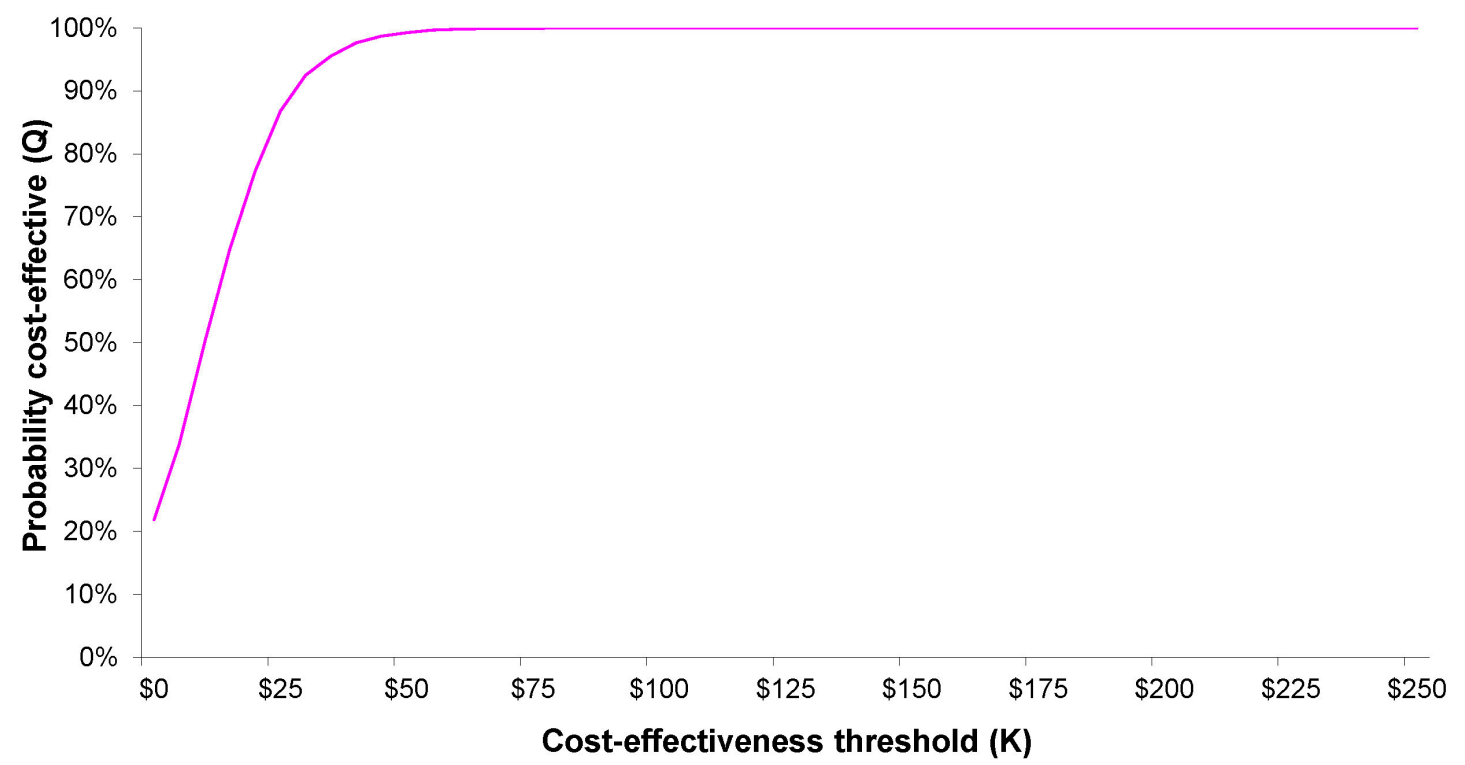

Figure 2 Cost-effectiveness acceptability curve STAT versus traditional waitlist for the probability of cost-effectiveness (vertical axis) versus a range of cost-effectiveness willingness to pay values (\$A) per day reduction in waiting time (horizontal axis). STAT, Specific Timely Appointments for Triage.

Distributing costs over 12 months, the ICER shows a cost of $\$$ A4 (95\% CI -25 to 32) per day of reduction in waiting time with STAT. The curve shows a $67 \%$ probability that the additional cost of STAT, compared with traditional waitlist, was at or below $\$ A 10$ per day of waiting saved.

\section{DISCUSSION}

The findings from this study show a significant reduction in waiting time for community outpatient services following the introduction of the STAT model, at minimal cost to the health system. Modelling showed that the probability of STAT implementation approaching cost neutrality would increase over a 6 -month and 12-month period post-implementation.

STAT, involving targeted investment coupled with a change in model of service delivery to address the underlying mechanisms that contribute to the development of waiting lists, was cost-effective. Therefore, implementation of STAT is likely to result in a better use of resources than some alternatives. Previous research with much larger investments to tackle waiting lists by reducing backlogs has been ineffective. ${ }^{731}$ Kenis argued that attempts to combat waiting lists by simply adding resources to increase supply without changes to service delivery ignores the complexity of the problem. ${ }^{31}$

The reduction in waiting time, at minimal cost to the health system, supports previous findings that waiting times are not typically a result of lack of capacity, but related to suboptimal allocation of resources. ${ }^{32}$ Shorter waiting times have been shown to be associated with improved patient outcomes and may alleviate some of the anxiety patients experience while awaiting health interventions. ${ }^{9}{ }^{12}$ Furthermore, clinicians report increased flexibility in their scheduling and a perception of a more efficient service when using the STAT model. ${ }^{9}{ }^{33}$ Therefore, in addition to its relatively low cost, STAT is a model that has the potential to improve patient outcomes and appears to be well accepted by clinicians. ${ }^{912}$

Although this study did not measure the return on investment from a societal perspective, it is possible that there are also benefits for the patients referred to the community outpatient services. For patients of working

Table 4 Mean total health system cost (SD) of health service in STAT and post and traditional waitlist periods and mean $(95 \% \mathrm{Cl})$ difference between groups $(\$ \mathrm{~A})$ and ICERs modelled at 6 and 12 months post-STAT implementation

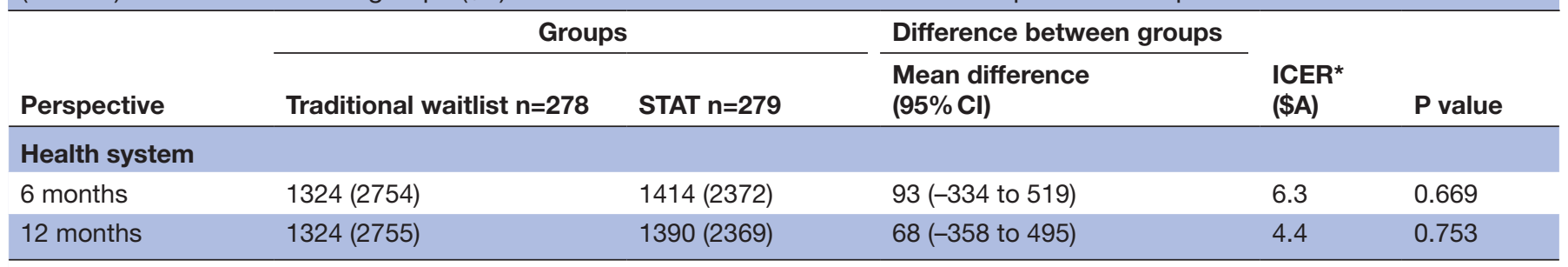

Between-group mean difference calculated using service as a covariate.

${ }^{\star}$ Cost per day of reduced waiting time.

.ICER, incremental cost-effectiveness ratio; STAT, Specific Timely Appointments for Triage. 
age, these benefits may include a reduction in loss of work income, as one of the benefits of reduction in waiting time for patients referred to community outpatient services includes decreasing work absenteeism. ${ }^{11} 1234$ For children and older patients, these benefits may include a reduction in the costs associated with informal care. Earlier access to community-based therapy may facilitate a more rapid functional recovery (eg, rehabilitation of the underlying impairment) or introduce a compensation strategy (eg, prescription of walking aid) to enable earlier participation in the home, school or workplace and reduced dependence on others. ${ }^{35}$

In a UK study, Propper estimated the population willingness to pay to avoid waiting for non-urgent outpatient treatment under the National Health Service. ${ }^{13}$ Their findings suggested a willingness to pay of $£ 40$ per month in 1987 (which equates to $\$ 183$ per month in \$A 2017, or $\$$ A6 per day). ${ }^{13}$ This is consistent with our result of \$A4-\$A6 per day saved in reduced waiting time suggesting that the cost of implementing STAT is likely to be within community expectations of the value of reduced waiting time.

In our study, participants in the STAT group were observed to have higher AQOL utility scores at admission to health service than participants in the traditional waitlist group; a difference of 0.03 units that approached but did not reach significance. If a genuine difference exists, one interpretation of this finding is that difference in the baseline characteristics of groups is a limitation of the study. An alternative explanation is that observed reductions in health-related quality of life in participants in the traditional waitlist group were due to a deterioration in health status during the waiting period. Systematic reviews have demonstrated that patients experience significant declines in both physical and psychological health with longer wait times for health services. ${ }^{1236}$ Clinicians identified that the main advantage of the STAT model was that patients could receive a healthcare intervention sooner which had positive impacts on their health outcomes. ${ }^{33}$ Therefore, it is possible that patients in the STAT group may have been healthier at the time of admission because they had a shorter wait time for health service input. Consequently, it is difficult to predict the directional relationship between utility scores and healthcare costs.

Implementing STAT involves a one-off financial investment to reduce the waiting list, followed by the introduction of strategies to maintain patient flow at the rate of demand. Therefore, the return on investment of STAT should improve with time as more patients receive timely services. Our modelling showed that the cost per day of waiting saved reduced from \$A9 3 months after STAT implementation to $\$ \mathrm{~A} 4$ if the benefits are maintained at 12 months. A 12-month follow-up, evaluation to the main trial showed that these benefits are mostly maintained with a 29\% reduction in waiting time attributable to STAT over 12 months, compared with $34 \%$ in the original trial. ${ }^{37}$ However, results varied between services, possibly indicating that there were differences in compliance with
STAT processes between services including ongoing estimation of demand. ${ }^{37}$ The original trial was not powered to explore the differences between sites and this could be addressed in future research.

There was a large variation in the cost of implementing STAT at the eight participating services. These costs were influenced by the size of the residual waiting list, the degree of specialty (and subsequent cost of supply) of the services provided and the availability of professionals to support backlog reduction strategies. For example, several services were able to increase hours of existing staff to address the existing waiting list, but one that did not have this opportunity contracted private practitioners at much higher cost. Services involved in previous trials of STAT have been able to implement the model at no cost, by using strategies such as timing the introduction of the intervention to seasonal reductions in referral numbers. ${ }^{27} 38$ The implementation costs reported in this study represent the combined experience of eight separate sites and therefore provide policymakers with a broad indication of costs of implementation.

Findings from the main STAT trial suggest that STAT was most likely to benefit patients who waited the longest for an appointment. ${ }^{17}$ This means that those who waited the shortest to receive an appointment may have received little benefit from the STAT intervention. Weighted mean waiting time at the 10th percentile increased by 1.1 days with STAT, although this first appointment was still within 10 days of referral. A limitation of our study is that we were unable to determine the impact of STAT on patients who would be categorised as 'high' need by clinicians using a triage approach under a traditional waitlist model. However, the STAT model incorporated systems for emergency appointments for patients with immediate clinical needs, ensuring that those with 'high' clinical needs could immediately access the service and were not disadvantaged. Also, in our main trial, STAT had no detrimental effects on outpatient care or outcomes, with no increase in the number of unplanned hospital readmissions or decrease in the number of review appointments. ${ }^{17}$ Therefore, it is unlikely that patients with a 'high' clinical need were disadvantaged by the STAT model.

A limitation of our study is that return on investment was not calculated from a societal perspective. Initially, we had planned to include patient outcomes (quality of life, cost of informal care, cost of employment hours lost). However, due to difficulties with patient follow-up, we were unable to obtain sufficient complete data for analysis in our study. ${ }^{16}$ We also had limited access to hospital administration data to determine the cost of emergency department presentations and hospital admissions. We therefore modelled the costs of these services based on assumptions from the information we had and publicly available hospital data sources. Using a pre-post design could increase the risk of bias in the results. However, this study was nested within a larger stepped-wedge randomised controlled trial and estimates of effect on reducing waiting time were similar to those observed in 
the larger trial. ${ }^{17}$ Also, the relatively large sample size and demonstration of baseline equivalence for key factors increase confidence in our results. The apparent discrepancy between overall cost of STAT implementation (\$A105 per patient) and cost within this study (\$A121 per patient) was due to variations in the proportion of participants included in each site in the two studies. Participants were not told whether they were attending the service within the pre-period or post-period. This blinding of participants is a strength of this study as it reduces the potential influence of bias. Another strength is the diversity of clinical services that the eight participating sites provided. This increases the generalisability of our findings to other public health networks.

\section{CONCLUSIONS}

STAT significantly reduced waiting times for patients referred to public community outpatient services at minimal cost to the health system. Modelling showed that the probability of STAT being cost neutral increased over a 6-month and 12-month period post-implementation. These results support the implementation of STAT across a variety of community outpatient services as a costeffective way to reduce patient waiting time by matching capacity with demand.

\section{Author affiliations \\ ${ }^{1}$ Peninsula Clinical School, Central Clinical School, Monash University, Frankston, Victoria, Australia \\ ${ }^{2}$ Allied Health Clinical Research Office, Eastern Health, Box Hill, Victoria, Australia \\ ${ }^{3}$ School of Allied Health, Human Services and Sport, La Trobe University, Bundoora, Victoria, Australia \\ ${ }^{4}$ School of Psychology and Public Health, La Trobe University, Bundoora, Victoria, Australia \\ ${ }^{5}$ School of Public Health, Harbin Medical University, Harbin, People's Republic of China \\ ${ }^{6}$ School of Nursing and Midwifery, Plymouth University, Plymouth, UK \\ ${ }^{7}$ School of Health and Social Development, Faculty of Health, Deakin University, Burwood, Victoria, Australia}

Twitter Nicholas F Taylor @EH_Research and Bridie Kent @BridieKent

Contributors DAS made substantial contributions to the acquisition of data, analysis and interpretation of data. JJW made substantial contributions to the study conception, design, analysis and interpretation of data. KEH, SGL, BK and NFT made substantial contributions to the study conception, design and interpretation of data. AKL made substantial contributions to the acquisition and interpretation of data. DAS and JJW drafted the manuscript. All authors revised the manuscript and agree to be accountable for all aspects of the work.

Funding This work was supported by the National Health and Medical Research Council of Australia through a Partnerships for Better Health Grant (APP 1076777), with contributions from industry partners Eastern Health (in-kind) and the Victorian Department of Health and Human Services (direct and in-kind).

Disclaimer Funders had no role in design, conduct or reporting of the trial.

Competing interests None declared.

Patient consent for publication Not required.

Ethics approval The trial was approved by the Eastern Health Human Research Ethics Committee (E06-2014) of the health network and university, and all patients provided written informed consent.

Provenance and peer review Not commissioned; externally peer reviewed.

Data availability statement The datasets generated and/or analysed during the current study are not publicly available due to conditions of ethical approval for the trial but are available from the corresponding author on reasonable request.
Supplemental material This content has been supplied by the author(s). It has not been vetted by BMJ Publishing Group Limited (BMJ) and may not have been peer-reviewed. Any opinions or recommendations discussed are solely those of the author(s) and are not endorsed by BMJ. BMJ disclaims all liability and responsibility arising from any reliance placed on the content. Where the content includes any translated material, BMJ does not warrant the accuracy and reliability of the translations (including but not limited to local regulations, clinical guidelines, terminology, drug names and drug dosages), and is not responsible for any error and/or omissions arising from translation and adaptation or otherwise.

Open access This is an open access article distributed in accordance with the Creative Commons Attribution Non Commercial (CC BY-NC 4.0) license, which permits others to distribute, remix, adapt, build upon this work non-commercially, and license their derivative works on different terms, provided the original work is properly cited, appropriate credit is given, any changes made indicated, and the use is non-commercial. See: http://creativecommons.org/licenses/by-nc/4.0/.

\section{ORCID iDs}

David A Snowdon http://orcid.org/0000-0003-2041-3120

Nicholas F Taylor http://orcid.org/0000-0001-9474-2504

Sandra G Leggat http://orcid.org/0000-0002-2252-4302

Jennifer J Watts http://orcid.org/0000-0001-8095-8638

\section{REFERENCES}

1 Lynch ME, Campbell FA, Clark AJ, et al. Waiting for treatment for chronic pain - a survey of existing benchmarks: toward establishing evidence-based benchmarks for medically acceptable waiting times. Pain Res Manag 2007;12:245-8.

2 Rastall M, Fashanu B. Hospital physiotherapy outpatient department waiting Lists. Physiotherapy 2001;87:563-72.

3 Raymond $\mathrm{M}-\mathrm{H}$, Demers L, Feldman DE. Waiting list management practices for home-care occupational therapy in the province of Quebec, Canada. Health Soc Care Community 2016;24:154-64.

4 Harding KE, Robertson N, Snowdon DA, et al. Are wait Lists inevitable in subacute ambulatory and community health services? A qualitative analysis. Aust. Health Review 2018;42:93-9.

5 Green L. Queuing analysis in health care. In: Hall RW, ed. Patient flow: reducing delay in healthcare delivery. Boston, MA: Springer, 2013.

6 Kreindler SA. Watching your wait: evidence-informed strategies for reducing health care wait times. Qual Manag Health Care 2008;17:128-35.

7 Kreindler SA. Policy strategies to reduce waits for elective care: a synthesis of international evidence. Br Med Bull 2010;95:7-32.

8 Palvannan RK, Teow KL. Queueing for healthcare. J Med Syst 2012;36:541-7.

9 Harding KE, Taylor NF, Bowers B. Perspectives of clinicians and patients following introduction of a new model of triage that reduced waiting time: a qualitative analysis. Aust Health Rev 2013;37:324-30.

10 Johnson DA, Sacrinty MT, Gomadam PS, et al. Effect of early enrollment on outcomes in cardiac rehabilitation. Am J Cardiol 2014;114:1908-11.

11 Zigenfus GC, Yin J, Giang GM, et al. Effectiveness of early physical therapy in the treatment of acute low back musculoskeletal disorders. J Occup Environ Med 2000;42:35-9.

12 Lewis AK, Harding KE, Snowdon DA, et al. Reducing wait time from referral to first visit for community outpatient services may contribute to better health outcomes: a systematic review. BMC Health Serv Res 2018;18:869.

13 Propper C. Contingent valuation of time spent on NHS waiting Lists. Econ J 1990;100:193-9.

14 Harding KE, Taylor NF, Leggat SG. Do triage systems in healthcare improve patient flow? A systematic review of the literature. Aust Health Rev 2011;35:371-83.

15 Murray M, Berwick DM. Advanced access: reducing waiting and delays in primary care. JAMA 2003;289:1035-40.

16 Harding KE, Watts JJ, Karimi L, et al. Improving access for community health and sub-acute outpatient services: protocol for a stepped wedge cluster randomised controlled trial. BMC Health Serv Res 2016;16:364.

17 Harding KE, Leggat SG, Watts JJ, et al. A model of access combining triage with initial management reduced waiting time for community outpatient services: a stepped wedge cluster randomised controlled trial. BMC Med 2018;16:182.

18 Rose KD, Ross JS, Horwitz LI. Advanced access scheduling outcomes: a systematic review. Arch Intern Med 2011;171:1150-9. 
19 Husereau D, Drummond M, Petrou S, et al. Consolidated health economic evaluation reporting standards (CHEERS)--explanation and elaboration: a report of the ISPOR health economic evaluation publication guidelines good reporting practices task force. Value Health 2013;16:231-50.

20 Transport Accident Commission. Fee schedules 2016/17, 2017 Available: http://www.tac.vic.gov.au/providers/invoicing-and-fees/ fee-schedules [Accessed 21 Nov 2017].

21 Australian Government. Medicare benefits schedule online, 2017. Available: http://www9.health.gov.au/mbs/search.cfm [Accessed 21 Nov 2017].

22 Independent Hospital pricing authority. National weighted activity unit (NWAU) non-admitted outpatient calculator 2016-17, 2017. Available: https://www.ihpa.gov.au/what-we-do/pricing/nationalweighted-activity-unit-nwau-calculators/nwau-calculators-2016-17 [Accessed 21 Nov 2017].

23 Independent Hospital Pricing Authority. National weighted activity unit (NWAU) emergency department calculator 2016-17, 2017. Available: https://www.ihpa.gov.au/what-we-do/pricing/nationalweighted-activity-unit-nwau-calculators/nwau-calculators-2016-17 [Accessed 21 Nov 2017].

24 Australian Government. Admitted patient care 2015-16: Australian hospital statistics, 2017. Available: https://www.aihw.gov.au/ getmedia/3e1d7d7e-26d9-44fb-8549-aa30ccff100a/20742.pdf.aspx? inline=true [Accessed 21 Nov 2017].

25 Richardson J, Elsworth G, lezzi A. Increasing the sensitivity of the $A Q o L$ inventory for the evaluation of interventions affecting mental health. Melbourne, AUS: Centre for Health Economics, Monash University, 2011.

26 Richardson J, Sinha K, lezzi A. Modelling the utility of health states with the assessment of quality of life (AQoL) $8 D$ instrument: overview and utility scoring algorithm. Melbourne, AUS: Centre for Health Economics, Monash University, 2011.

27 Harding KE, Leggat SG, Bowers B, et al. Reducing waiting time for community rehabilitation services: a controlled before-and-after trial. Arch Phys Med Rehabil 2013;94:23-31.
28 Nixon RM, Wonderling D, Grieve RD. Non-Parametric methods for cost-effectiveness analysis: the central limit theorem and the bootstrap compared. Health Econ 2010;19:316-33.

29 IBM Corp. Ibm SPSS statistics for windows, version 24.0. Armonk, NY: IBM Corp, 2016.

30 Briggs A, Fenn P. Confidence intervals or surfaces? uncertainty on the cost-effectiveness plane. Health Econ 1998;7:723-40.

31 Kenis P. Waiting Lists in Dutch health care: an analysis from an organization theoretical perspective. $J$ Health Organ Manag 2006;20:294-308.

32 Silvester K, Lendon R, Bevan $\mathrm{H}$. Reducing waiting times in the NHS: is lack of capacity the problem? Clin Manag 2004;12:105-9.

33 Harding KE, Snowdon DA, Lewis AK, et al. Staff perspectives of a model of access and triage for reducing waiting time in ambulatory services: a qualitative study. BMC Health Serv Res 2019;19:283.

34 Linton SJ, Hellsing A-L, Andersson D. A controlled study of the effects of an early intervention on acute musculoskeletal pain problems. Pain 1993;54:353-9.

35 Australian Government. Review of Australian government health workforce programs: allied health workforce, 2013. Available: http:// www.health.gov.au/internet/publications/publishing.nsf/Content/ work-review-australian-government-health-workforce-programs-toc chapter-8-developing-dental-allied-health-workforce chapter-8allied-health-workforce [Accessed $6 \mathrm{Jul}$ 2019].

36 Lynch ME, Campbell F, Clark AJ, et al. A systematic review of the effect of waiting for treatment for chronic pain. Pain 2008;136:97-116.

37 Harding KE, Snowdon DA, Prendergast L, et al. Sustainable waiting time reductions after introducing the STAT model for access and triage: 12-month follow up of a stepped wedge cluster randomised controlled trial. BMC Health Serv Res 2020;20:968.

38 Harding KE, Bottrell J. Specific timely appointments for triage reduced waiting Lists in an outpatient physiotherapy service. Physiotherapy 2016;102:345-50. 